\title{
IMPACT OF PENGUIN BIOTRANSPORT ON THE FLORAL LANDSCAPE OF ThE SOUTH SANDWICH IsLANDS
}

\author{
Max GOTTS ${ }^{* \dagger \bowtie ~ \& ~ D Y L A N ~ J . ~ T A Y L O R ~}{ }^{* \otimes}$ \\ * Nueva School, San Mateo, California 94403, USA \\ $\dagger$ Lost Years Institute, Mill Valley, California 94941, USA \\ $\bowtie$ maxgott@nuevaschool.org, dyltayl@nuevaschool.org
}

\begin{abstract}
RESEARCH QUESTION
To what extent is local flora influenced by ornithogenic soil biochemical-composition in the South Sandwich Islands, with special attention given to Zavodovski Island, and what are the down-stream effects on the geology of the islands?
\end{abstract}

\section{HYPOTHESIS}

Areas supplied by fluvial run-off from penguin colonies, especially crêches, host the most productive and species rich floral landscapes, even after controlling for geothermal activity.

Keywords biogeochemical linkage $\cdot$ biotransport $\cdot$ floral landscape $\cdot$ penguin colony $\cdot$ south sandwich islands

\section{INTRODUCTION}

Though the Antarctic and sub-Antarctic are lacking in fauna relative to the other continents, the few creatures that do inhabit the island - Weddell seals, molluscs, and numerous species of penguin - can offer invaluable insight into the ecological makeup of Antarctica. These animals help create an evolving landscape of chemicals that has yet to be studied in great detail. As such, this proposal looks into chinstrap penguin-controlled marine-terrestrial biogeochemical linkage and its influence on local flora.

The study of marine-terrestrial biogeochemical interactions is a highly complex and involved, yet understudied, topic in geo-ecology. Geochemical processes can, in many cases, be the limiting factors in a biological system and so our lack of knowledge is inexcusable. Even despite this dearth of knowledge, it has become clear that there are biogeochemical marine-terrestrial links that play critical roles in the stabilization of chemicals necessary for the perpetuation of local and global ecologies (cf. Ridgwell \& Kohfeld 2005).
The volcanic-driven geochemical composition of the South Sandwich Islands is well known (Gass et al. 1963), but it was Ugolini (1972) who was among the first to discover that penguin droppings, which create ornithogenic soils suitable to floral growth, is the most extensive source of organic matter for the terrestrial ecosystems. Subsequent studies (cf. Heine and Speir 1989, Liguang et al. 2004) have demonstrated that penguin excrement has a direct effect on local biomes. Through using geochemical markers, Liguang et al. discovered an inverse relationship between penguin population density and floral growth: after the birds had departed the island, the researchers found floral growth flourished due to fertile soils. They suggested, then, that a comprehensive population history of local penguins could be recreated using extracted soil cores, an idea further demonstrated in Emslie et al. (2014).

In attempting to demonstrate the causative link between penguin droppings and floral growth, Guo et al. (2018) postulated two mechanisms. First, the moisture content of ornithogenic soils is pos- 
itively correlated with the number of droppings; in the potentially dry (with respect to precipitation) landscape of Antarctica, increased moisture is crucial. Second, nutrient enrichment occurs due to elevations of carbon, nitrogen, phosphorus, and silicon. The link between penguins and geochemical altercations of local soil was first expressed in Liguang et al. (2004), who used an chemical array of sulfur, phosphorous, calcium, copper, zinc, selenium, strontium, barium, and fluorine to infer historical penguin density. Like Guo et al. (2018), the researchers demonstrated that nitrogen and phosphorus were strongly correlated with penguin droppings. However, toxification of the soil can occur in particularly dense colonies, precluding floral growth through both trampling and metal prevalence. For instance, Santamans et al. (2017) showed that penguin droppings promote biotransport of certain chemical pollutants, especially copper, zinc, and selenium, as well as significant amounts of organic carbon. Adjustments to the soil microbiota (e.g dominance of enteric bacteria) was similarly found to have an effect on local flora. As such, Liguang et al. (2004) equivalently shows toxification and heavy metal biotransport occurs during active periods in penguin colonies, which prevents immediate floral growth. The positive effects resulting from penguin presence, namely enhanced moisture content and nutrient enrichment, persists post-departure (or downstream of the colony), which eventually creates a suitable environment for plant growth.

The flora of the Antarctic and sub-Antarctic is much less well-studied. Convey et al. (2000) show that magnitude of geothermal heating is an important factor in floral composition of an area: sub-Antarctic flora can only survive in such places, whereas Antarctic flora is more often found in cooler zones. Other than this, we have very little knowledge of the variables that influence floral composition. This lack of knowledge is especially troublesome given the imminent threat of climate change. Outside of Singh et al. (2018), little literature has explored the relationship between warmer temperatures and Antarctic flora. Examining causative factors behind floral growth-namely biochemical transport-is thereby integral to un- derstanding the uncertain future of sub-Antarctic plant life, especially given the likelihood of increased fluvial runoff caused by rises in temperature.

As such, it is integral to determine how biochemical transport influences the floral landscape of the sub-Antarctic geographic area. This study would discover the nature - or refute the existence - of such a relationship.

\section{Methods}

This experiment will take place on Zavodovski $\left(56.2996^{\circ} \mathrm{S}, 27.5704^{\circ} \mathrm{W}\right)$, a constituent island of South Georgia and the South Sandwich Islands. Zavodovski Island is a relatively small island-six square miles in size - with a documented history of sustained penguin habitation (Barr 2000, c.f. Mori 1997, Bustamante \& Márquez 1996). As outlined below, we will dictate four treatments (each with individual n-values of multiple locations). Soil cores would be extracted using a PVC pipe then $\mathrm{x}$ rayed to determine the chemical composition, looking specifically at organic carbon, heavy metals, and phosphates. Using proven fingerprint geochemicals of droppings (see Measurements: 3.), we can infer the relative density of excrement by location and, by extension, how far the droppings are transported fluvially. These results would finally be cross-referenced with floral density at each treatment to create a quantifiable relationship between inferred dropping prevalence (using geochemical profiling as a proxy) and floral growth. The additional variable of ground temperature would be recorded to explain potential discrepancies (i.e confounding variables) in the data (see Convey et al. 2000).

Treatments (with multiple locations per treatment)

1. Within colony

2. Border of colony (i.e depression zone)

3. Downstream (i.e. fluvially) of colony

4. Non-downstream (e.g. upstream) of colony

Measurements

1. Moisture content

2. Organic carbon content 
3. Sulphur, $\mathrm{P}_{2} \mathrm{O}_{5}, \mathrm{CaO}$, copper, zinc, selenium, strontium, barium, fluorine content (sensu Liguang et al. 2014)

4. Heavy metal concentrations

5. Proximity of treatment site from closest penguin colony

6. Density of penguins

7. Floral density (species richness, type, physical density)

8. Floral species

9. Ground temperature (at a consistent depth)

\section{Potential Challenges}

Some central challenges facing this proposal are as follows: remote nature of the Zavodovski Island, inclement weather caused by far-southern latitude, inhospitality and lack of human settlement on the island, and logistical challenges associated with accessing the island safely. With proper funding, we believe that each challenge can be overcome. Funding for this proposal would go towards acquiring transport to the island (by research vessel or otherwise), establishing hospitable conditions (e.g temporary research tent) on the island's south flank, and purchasing/gaining access to equipment necessary for attaining quantifiable results (e.g PVC pipe, radiometric chemical array), and RAP Category 1 permits to allow such research to be conducted (GSGSSI a, b).

In rough seas or violently inclement weather, we may have to abort or delay any mission to access the island. This would be regrettable, but above all else we wish to preserve human life on this trip: collecting data comes second to this always. However, we are confident that a window of opportunity to access the island will be feasible, as demonstrated by the first recorded landings of humans on Zavodovski Island in 1819: "[we] landed easily amongst rocks [of Zavodovski Island]" (Barr 2000).

\section{BIBLIOGRAPHY}

Barr, W. (2000). First landings on Zavodovski Island, South Sandwich Islands,
1819. Polar Record, 36(199), 317. doi:10.1017/s0032247400016806

Government of South Georgia \& the South Sandwich Islands (n.d.). Permits, Gov.gs. http://www.gov.gs/science-2/science/

Government of South Georgia \& the South Sandwich Islands (n.d.). Regulated Access Permits, Gov.gs. http://www.gov.gs/visitors/regulatedactivity-permit/

Bustamante, J., \& Márquez, R. (1996). Vocalizations of the Chinstrap Penguin Pygoscelis antarctica. Colonial Waterbirds, 19(1), 101-110. doi: $10.2307 / 1521812$

Convey, P., Lewis Smith, R. I., Hodgson, D. A., \& Peat, H. J. (2000). The flora of the South Sandwich Islands, with particular reference to the influence of geothermal heating. Journal of Biogeography, 27(6), 1279-1295. doi:10.1046/j.1365-2699.2000.00512.x

Emslie, S. D., Polito, M. J., Brasso, R., Patterson, W. P., \& Sun, L. (2014). Ornithogenic soils and the paleoecology of pygoscelid penguins in Antarctica. Quaternary International, 352, 4-15. doi:10.1016/j.quaint.2014.07.031

Guo, Y., Wang, N., Li, G., Rosas, G., Zang, J., Ma, Y., ... Cao, H. (2018). Direct and Indirect Effects of Penguin Feces on Microbiomes in Antarctic Ornithogenic Soils. Frontiers in $\mathrm{Mi}$ crobiology, 9. doi:10.3389/fmicb.2018.00552

Heine, J. C., \& Speir, T. W. (1989). Ornithogenic soils of the cape bird adelie penguin rookeries, Antarctica. Polar Biology, 10(2). doi: $10.1007 /$ bf00239153

Hegerl, G. C. (2005). OCEAN SCIENCE: Warming the World's Oceans. Science, 309(5732), 254-255. doi:10.1126/science.1114456

Mori, Y. (1997). Dive bout organization in the Chinstrap penguin at seal island, antarctica. Journal of Ethology, 15(1), 9-15. doi:10.1007/bf02767321

Liguang, S., Renbin, Z., Xuebin, Y., Xiaodong, L., Zhouqing, X., \& Yuhong, W. (2004). A geochemical method for the reconstruction of the occupation history of a penguin colony in the maritime Antarctic. Polar Biology, 27(11), 670-678. doi:10.1007/s00300-004-0635-z Santa- 
mans, A. C., Boluda, R., Picazo, A., Gil, C., Singh, J., Singh, R. P., \& Khare, R. (2018). InfluRamos-Miras, J., Tejedo, P., ... Camacho, A. ence of climate change on Antarctic flora. Polar (2017). Soil features in rookeries of Antarctic Science. doi:10.1016/j.polar.2018.05.006 Ugolini, penguins reveal sea to land biotransport of chemical pollutants. PLOS ONE, 12(8), e0181901. doi:10.1371/journal.pone.0181901 F.C. Ornithogenic Soils of Antarctica. Antarctic Terrestrial Biology, Antarctic Research Series, vol.20. doi:10.1002/9781118664667.ch9 